Dana L. Rohr

R. O. Elliott 
Printed in the Lnited States of America. Available from National Technical Information Service U.S. Depastment of Commerce

$$
\begin{aligned}
& 5285 \text { Port Royal Road } \\
& \text { Springficld. VA 22151 }
\end{aligned}
$$

Price: Printed Copy \$3.50 Microfiche \$2.25

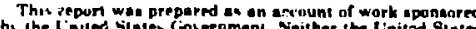

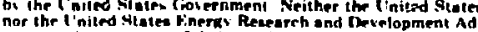
ministrstion. nar ans of their employers, nor anv of their can

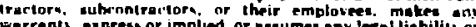

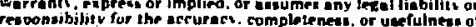
resu information. opperctun, product, ar proceus diaclocent, of represenis that ith une would nnt infringr privately owned rixhis. 


\title{
AN APPLICATION OF TRANSMISSION ELECTRON MICROSCOPY TO SPLAT-COOLED PLUTONIUM ALLOYS
}

by

Dana L. Rohr and R. O. Elliott

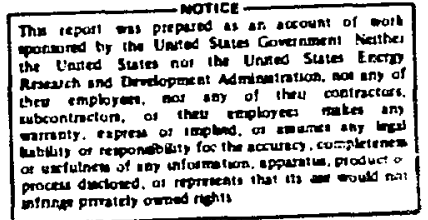

\begin{abstract}
Plutorium alloy foils, thin enough for transmission electron microscopy (TEM), were made by rapidly quenching small specimens from the melt in a "gun"-type, splat-cooling device. Microstructures in selected regions of the nonequilibrium alloys thus produced are illustrated and discussed. To our knowledge, all previous attempts to do TEM on plutonium and its alloys have failed.
\end{abstract}

\section{INTRODUCTION}

The earliest attempt to make plutunium samples for transmission microscopy at the los Alamos Scientific Laboratory (IASL) began in the fall of 1963, when rolled alpha (pure) and rolled delta (alloyed) sheets were thinned electrochemically. (See Ref. 1 for indirect reference.) The oxidationsensitive nature of plutonium invariably caused the end product $t o$ be a sandwich of thin metal between relatively thick layers of oxide. Such samples were unsuitable and the work was discontinued. Other workers $^{2-4}$ also tried electrothinning with similar results. As far as we know no other altempts have been made sirce 196i. At that time elaborate inerting systems seemed necessary for both the dry box and thinning equipment: such a scheme was considered by Wadleigh" but was never implemented. lon-thinning techniques were also considered," bue again experimental difficulties led io ahandonment of the effort.

In 1962 Willensi had shown that rapid yuenching from the melt (splat cooling) in a "gun" type ap. parat us produced thin foils suitable for THM. Since then it was known that this technicjue promised a way of obtaining TEM samples of plutonium allows. However, it was more than a decade later before a splat-cooling apparatus of this lype was built at LASL for work with plutoniun and other alpharadioactive materials." Briefly, this splat-cooling apparalus quenches samples by means of a shock pulse which ejects a bead of molten metal through a hole $\sim 1 \mathrm{~mm}$ in diameter in the bot tom of a ceramic crucible and onto a relatively massive copper or silver target plate. The force of the shock wave ejects the molten material from the crucible at high velocity as a fine spray of micron-sized droplets that impinge on the target plate. Rapidly quenched samples thus produced are porous in nature: nevertheless they are suitable for analysis by standard x-ray diffraction methods and. in some cases, hy TEM, as will be shown.

The porous, splatted deposit is made up of many thin foils of irregular size and shape that overlap in places and stick together. The thickness of individual foils varies from a few hundred angstroms near edges and around holes to many microns at the renter. Small chips of the splatted deposit can be lifted from the target plate with tweezers or a needle. Such chips or flakes were mounted between two elec. Iron microscope grids and placed in the microscope for examination. In nearly every case, the edges of such chips were transparent to the electron beam and proved quile suitable for viewing. Using standard precautions for handling alpha-radioactive materials.' the sample was taken from the vacuum at mosphere of the splat cooling apparat us and placed in the vacuum at mosphere of the microscope. Exposure to air was usually $10 \mathrm{~min}$ or less and no observable degradation of the semple surface occurred. 
However, in regions thin enough for electron transparency the samples often showed a heavy ozide deposit which prevented observation of the microstructure of the metal or alloy. Table $i$ lists the splat compositions examined by TEM. The plutonium-gallium alloys, pure plutonium deposits. and neptunium-cobalt alloys were particularly susceptible to oxidation based on electron diffrac. tion evidence. The patterns of all alloys examined were made up of a mixture of alloy and oxide spotc. These spots could be separated and indexed only with considerable difficulty under favorable circumstances. We also observed that when a sample was subjected to unusual electron beam heating it was converted to small grains of $\mathrm{PuO}_{2}$, as illustrated in Fig. 1. The electron diffraction pattern of the sample is shown in the lower left-hand corner of the figure. In the plutonium-titanium and plutoniumcerium systems, however, a few regions were found where, under normal operating conditions, the splat deposits showed only a thin oxide layer that did not obscure the structures of interest.

\section{DISCUSSION OF RESULTS}

A transmission electron micrograph of an as. deposited fcc $\bar{b}$-plutonium solid solution containing 18 at $\%$ titanium appears as Fig. 2. Bands of changing orientation. presumably twin bands or kink bands, are common; this might be expected in a material with a complex thermal and mechanical histery such as occurs during splat cooling and nonequilibrium solidification. Appearance of twin bands in Fig. 2 is in agreement with a very large twiuning fault probability in a nearly identical $\dot{o}$-plutonium alloy containing 15 at. "itanium, based on a linebrosdening effect in the $x$-ray diffraction pattern. 9 Particles, presumably of the equilibrium a-titanium phase. that have precipitated can be seen in the mutrix. The TEM evidence thus suggests that the $\delta$ phase in this 18 at."; titanium alloy may not have formed directly from the melt during rapid quenching, but rather that it might have been the prodluct of a solid-state martensitic transformation from the high-temperattre bec form of plutonium (E-phase).

The microstructure of another as-deposited $\delta$. plutonium solid solution containing 22.5 at. $" i$ cerium is shown in Fig. 3. Again, fine bands with a width of 50 to $80 A$ can be seen in the tigure, indicating that this alloy may also have been formed by transforming martensitically from an $\varepsilon$ plutonium solid solution during the quench. The streaked electron diffraction pattern in Fig. 3. indicates the existence of thin plates in the microstruc-
TABLE 1

\section{COMPOSITION OF SPLAT-COOLED SAMPLES EXAMINED BY TEM}

\author{
plutonium 40 at. "c titaniurn \\ plutonium 25 at. "c titanium \\ plutonium 20 at. "c titanium \\ plutonium 18 at." $i$ titanium \\ plutonium 5 at.": titanium \\ plutonium 30 at." cerium \\ plutonium 25 at.' $;$ cerium \\ plutonium $22-1 / 2$ at $" t$ cerium \\ plutonium 5 at $"$ " cerium \\ plutonium 45 at ' $" ;$ gallium \\ plutonium 35 at."; gallium \\ plutonium 25 at." gallium \\ plutonium 20 at. $\because$ gallium \\ plutonium $17-1 / 2$ a! $\because$ gallium \\ plutonium $1 \bar{s}$ at. $\%$ gnllium \\ plutonium $12-1 / 2$ at." gallium \\ plutonium $7-1 / 2$ at. $" r$ gallium \\ plutonium 3.1/2 at."; gallinm \\ plutosium 12 at." nickel \\ neptunium it at." cobalt \\ a-plutonium
}

ture aligned parallel to the clectron beam, in agreement with the appearance of the twinning seen in the micrograph.

Splat cooling of binan and multi-component alloys has produced many amorphous phases. ${ }^{10}$ These are formed when molten alloys are quenched rapidly encugh to suppress erystallization and may be considered to be undercooled liquids. The presence of such a phase may have been found in selected regions of splat-cooled plutonium-gallium alloys, where microstructures in the 25 to 50 at. gallium range tended generally to appear free of structural details and where electron diffraction showed only very diffuse rings, as illustrated in Fig. 4. X-ray scattering patterns verifted the nonctystallinity in $45-i 0$ at. "allium alloys."

\section{SUMMARY}

Our experience with splat cooling by the "gun" technique has demonstrated a limited usefulness of that method as a tool for producing thin foils of plutonium alloys for TEM. This has enabled us for the first time to look at and photograph the microstructures of plutonium alloys by TEM methods. 


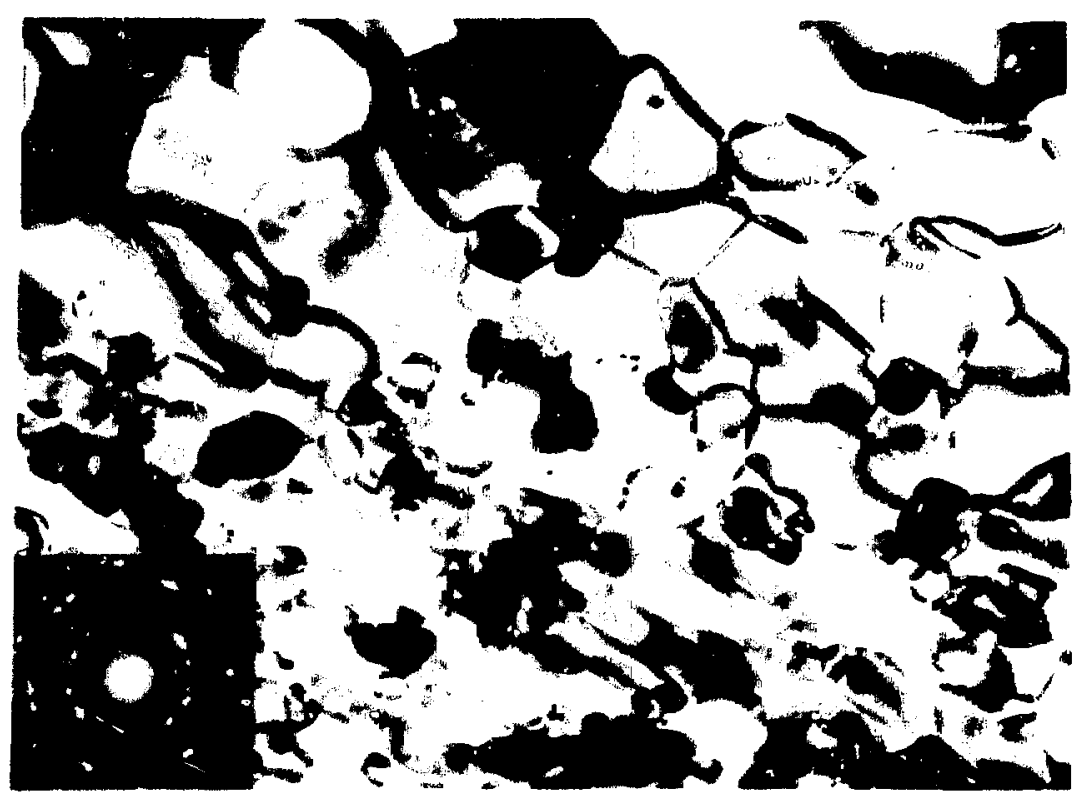

Fig. 1.

PuO.. crystallites formed by electron beam heating in the electron microscope. Magnification $=70000$.

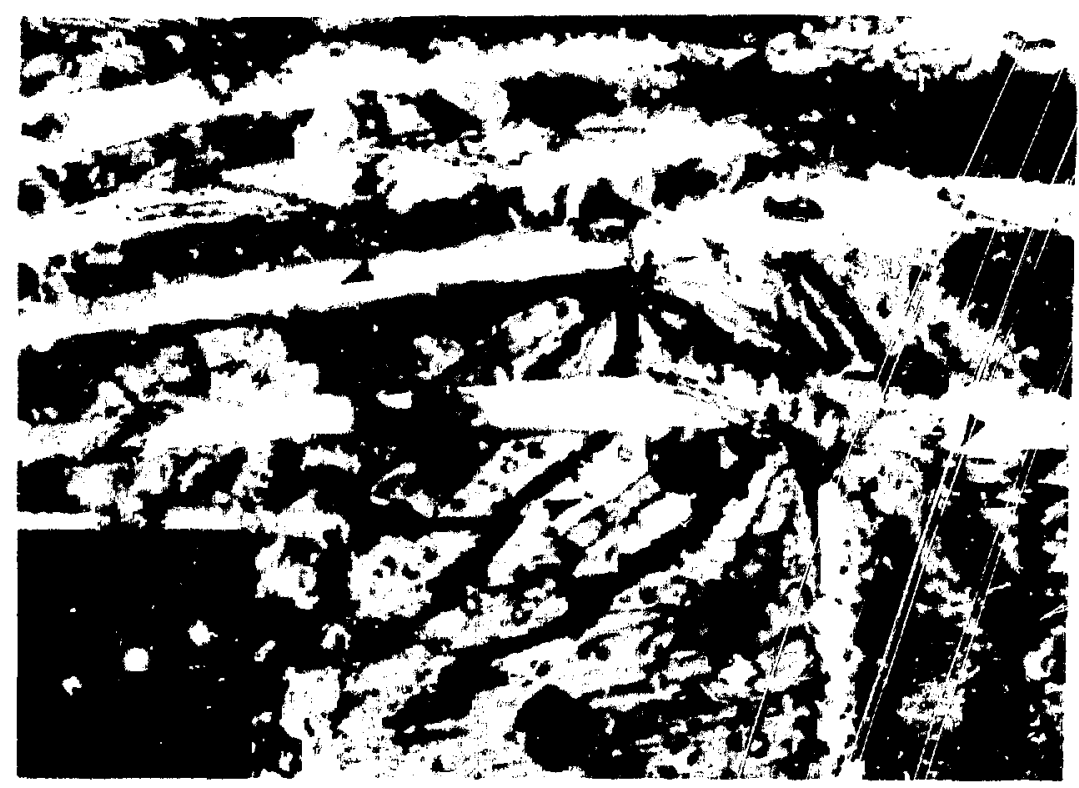

Fig. 2.

Fine twin bands in an 18 at.\% titanium-plutonium alloy. Magnification = 70000 . 


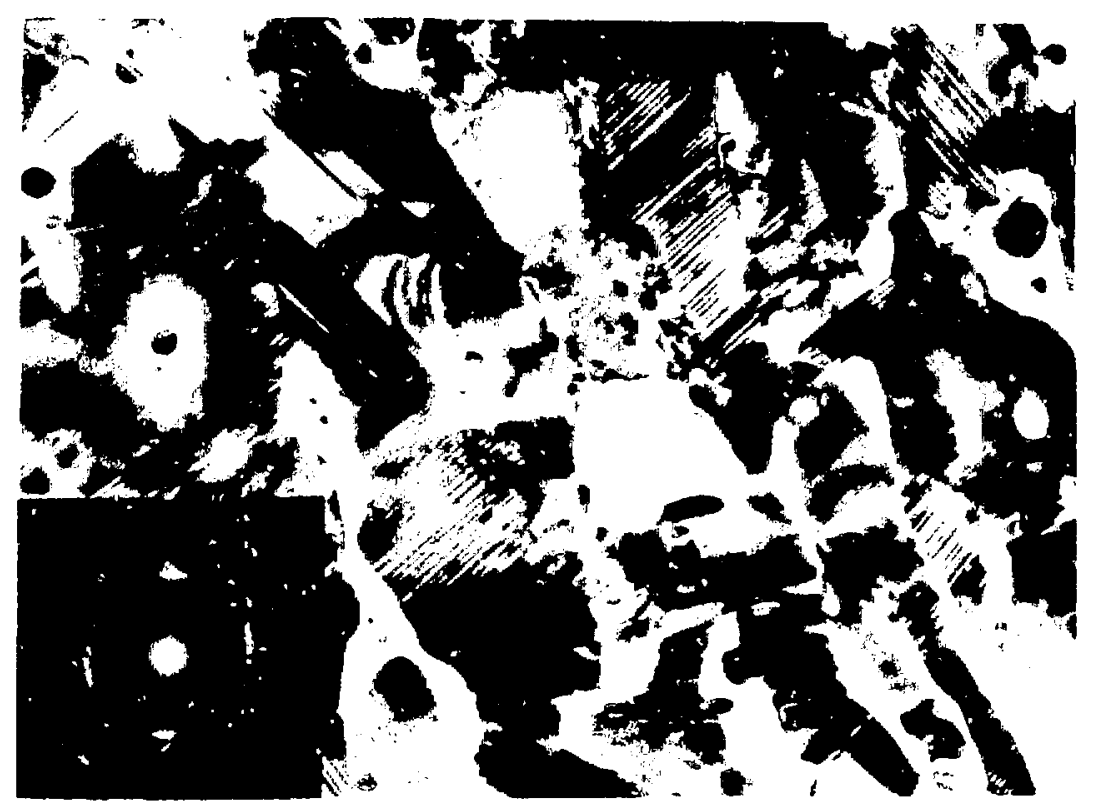

Fig. 3.

Microtwins in a 22-1/2 at.\% cerium-plutonium alloy. Magnification = 125000.

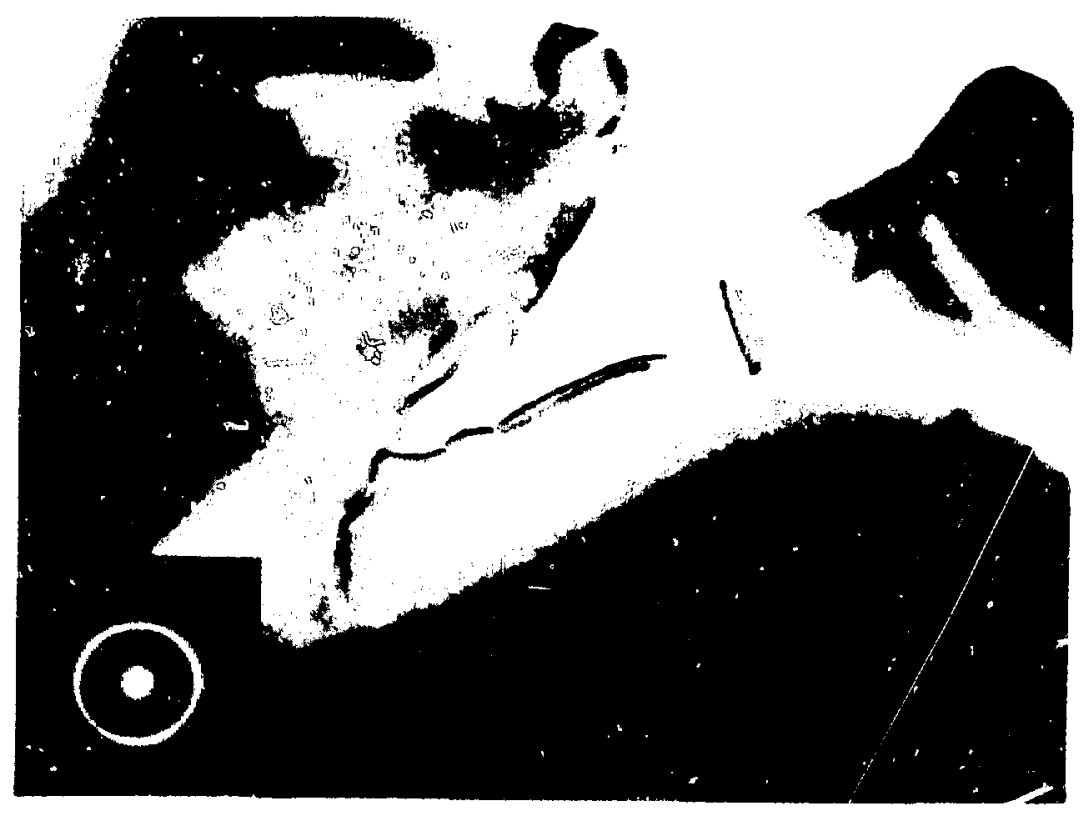

Fig. 4.

Amorphous phase in a 25 at.\% gallium-plutonium attoy. Magnification = 80000 


\section{REFERENCES}

1. D. L. Douglass, "Techniques for Handling Alpha-Active Specimens for Electron Microscopy," Los Alamos Scientific Laboratory report LA-3200 (March 1965).

2. A. W. Brewer and F. J. Fraikor, "Transmission Electron Microscopy of $\mathrm{Pu}$ - 1 wt.; Ga," J. Nucl. Mater. 21, 345-348 (1967).

3. D. L. Douglass and S. E. Bronisz, "Discussion of 'Transmission Electron Microscopy of $\mathrm{Pu}-1$ wt\% Ga' by A. W. Brewer and F. J. Fraikor," J. Nucl. Mater. 23, 107-108 (1967).

4. L. Ekbom, U. Johnaason, and M. Tornqvist, "An Electron Microscop: : Study of Plutonium," J. Nucl. Mater. 24, 230-231 (1967).

5. W. Wadleigh, Lawrence Livermore Laboratory, private communication, 1969.
6. J. W. Ward, "High-Vacuum Glow-Discharge Etcher and Ion-Thinner," Microstructures 2, 11-18 (1971).

7. R. H. Willens, "A New Method for Preparing Samples for Tranemission Electron Microscopy," Proc. 5th Int. Congr. Electron Microscopy, 5th, Philadelphia, 1962 (Academic Press, New York, 1962), Paper EE-6, Vol. I.

8. R. O. Elliott, A. M. Russell, and B. C. Giessen, "Retention of a Metastable bcc $\mathcal{E}$-Pu Solid Solution: $\varepsilon$-Pu(Ti)," J. Mater. Sci. 8, 1325-1330 (1973).

9. R. B. Roof and R. O. Elliott, "Evidenc? for the Existence of Faulting in a Splat-Cooled $\delta$-Pu (Ti) Alloy," J. Mater. Sci. 10, 101-108 (1975).

10. J. J. Gilman, “Metallic Glasses," Phys. Today 28, 46-53 (1y75).

11. R. O. Elliott and B. C. Giessen, unpublished work (1973). 